Khomenko Olena, Nekhanevych Oleh, Simonova Sofiia, Kovalenko Yevgeniia, Kosse Valentin, Topka Elvira. Stress resistance and adaptive capacities of cardiovascular system of graduating teenagers with different level of studying load. Journal of Education, Health and Sport. 2021;11(8):171-181. eISSN 2391-8306. DOI http://dx.doi.org/10.12775/JEHS.2021.11.08.017

https://apcz.umk.pl/czasopisma/index.php/JEHS/article/view/JEHS.2021.11.08.017

https://zenodo.org/record/5208226

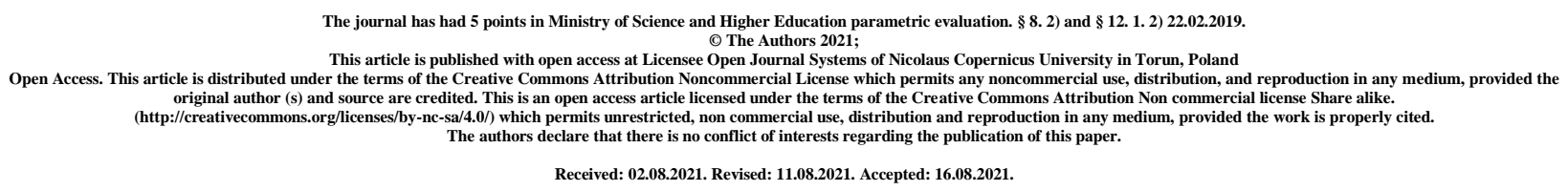

\title{
Stress resistance and adaptive capacities of cardiovascular system of graduating teenagers with different level of studying load
}

\author{
Olena Khomenko ${ }^{1}$, Oleh Nekhanevych ${ }^{2}$, Sofiia Simonova $^{2}$, Yevgeniia Kovalenko ${ }^{1}$, \\ Valentin Kosse ${ }^{3}$, Elvira Topka ${ }^{3}$ \\ ${ }^{1}$ Oles Honchar Dnipro National University \\ Gagarina Avenue, 72, Dnipro, 49010, Ukraine \\ ${ }^{2}$ Dnipro State Medical University \\ V.Vernadskogo str., 9, Dnipro, 49044, Ukraine \\ ${ }^{3}$ Dnipro Medical Institute of traditional and non-traditional medicine \\ Sevastopolska str., 17, Dnipro, 49000, Ukraine
}

Olena Khomenko: https://orcid.org/0000-0001-9341-6192

E-mail: khomenkoelen@gmail.com

Oleh Nekhanevych: https://orcid.org/0000-0003-0307-784X

E-mail: 202@dsma.dp.ua

Sofiia Simonova: https://orcid.org/0000-0001-7775-2495

E-mail: olenasim@gmail.com

Yevgeniia Kovalenko: https://orcid.org/0000-0002-7714-6177

E-mail: ri4tusik@gmail.com

Valentin Kosse: https://orcid.org/0000-0002-4620-7563

E-mail: dmitnm.1993@gmail.com

Elvira Topka: https://orcid.org/0000-0003-1177-3597

E-mail: duzenkoyana@gmail.com 


\begin{abstract}
The analysis of stress resistance and adaptive reactions of cardiovascular system was conducted according to the level of heart rate variability of graduating teenagers regardless of their studying load. The survey was held in Dnipro (Ukraine) based on a method of anonymous questioning using a personally developed and standardized questionnaire. 84 teenagers that are students of the $11^{\text {th }}$ form of comprehensive schools and lyceums were asked. 22 children of relevant age from different countries made up a comparison group, among them an online survey was conducted by means of similar English-language questionnaire in Google-form. The assessment of heart rate variability of 46 graduates was given, using a cloud technology of automated interpretation of ECG (PRECISE). Statistical processing was conducted using the application program Statistica 6.0 for Windows. Decreasing of stress resistance and significant violations of adaptive cardiovascular reactions in teenagers of graduating classes in Dnipro was set, especially in lyceum students as a result of insufficient rest of students. During the educational period significant violation of adaptive capabilities takes place in $65.6 \%$ of lyceum students: exhausting of functional organism's reserves with decline in RMSSD to (17.2 \pm 1.9$)$ meters per second, Total power to (607.25 \pm 11.9$)$ meters per second has been observed in half of the students. At the same time, 85.3 $\%$ of the comprehensive school students have sufficient adaptive and worse resource capacities of an organism. For the first time it was highlighted that the autonomous nervous system among the examined teenagers operates in the imbalance regime of its sympathetic and parasympathetic link with a prevalence of sympathicotonia among the $50 \%$ of lyceum students during a recessional period, $56.3 \%$ during an educational period, while vagotonia and eutonia prevail among the comprehensive school students, not depending on the school year period. It was found out that physical activity promoted increased body resistance to stress factors. The efficient determination of heart rhythm variability (PRECISE diagnostics) was proven to control the functional state and adaptive capabilities of graduates' cardiovascular system.
\end{abstract}

Key words: stress resistance; adaptation; cardiovascular system; teenagers; PRECISE diagnostics.

\title{
Introduction
}

In circumstances of modern life development (too high pace of life, instability, improvement of high technologies), in the background of physical activity (PA), the problem of stress is especially crucial due to the fact that people become more vulnerable to it $[1,2,3]$. According to WHO's data, half of all the mental illnesses start in the period of adolescence when social and emotional abilities, important for mental welfare, are developing and fixing however these illnesses are often identified and treated not timely. American Institute of Stress defines stress as a health problem №1 because prolonged stress effects cost to governments billion dollars per year $[4,5]$.

It is known that teenagers, especially comprehensive school students, are facing with a wide range of constant stress factors: significant academic requirements, increased information load (hard schooling, extra classes, prolonged use of gadgets) $[3,5]$. In post-Soviet countries there is a widespread practice of extracurricular classes after school in so called "tutors", the number and duration of which grow significantly in graduate classes that reduces time for teenagers' rest and results in a reduction of stress resistance [6].

The diagnostics of stress features among children and teenagers is acquiring an increasing urgency because actions for reducing the tension of functional organism's systems, taken timely, make it possible to stop negative results of the impact of adverse factors as well as to cease the developing of pathological changes [7].

Scientists have provided many methods to determinate the level of stress and stress resistance of people, among them there are questionnaire, cortisone level determination (that is quite expensive) etc. $[6,8,9,10]$, but for today there are no generally accepted standards for its evaluation $[11,12]$. 
It is aware that initial stage of stress reaction development is accompanied by hypothalamus activation which hormones stimulate adrenal activity and as a result the tonus of sympathetic branch of autonomous nervous system (ANS) is increasing [13-17].

Recently the PRECISE diagnostics has been introduced in Ukraine that helps to analyze the heart rate variability (HRV) of cardiovascular system (CVS) that reacts the very first to equilibrium fluctuations of ANS's departments, using cloud technology of automated EKG interpretation with analyze in more than 700 options based on the Minnesota code [18-21]. By means of the PRECISE diagnostics state of ANS, level of stress, adaptation and risk of cardiovascular disease can be analyzed. Data, based on the heart rate variability from 4 to 12 withdrawals, are gained within 5 minutes. This methodology has an international certificate, evidence base and, according to literature, is a highly effective instrument to control the risk factors of cardiovascular pathology development $[18,20]$.

The analyze of modern literature showed lack of researches in Ukrainewhich could explain the relationship between the day structure of graduating teenagers, level of their stress resistance and adaptive reactions of their cardiovascular system.

\section{Purpose}

To analyze the stress resistance and adaptive reactions according to the level of heart rate variability among graduating teenagers depending on their academic load.

\section{Materials and methods}

The research was held in Dnipro (Ukraine) during 2019 in three stages with the involvement of comprehensive school students of the $11^{\text {th }}$ form - I group (32 people: 15 boys and 17 girls) and students of specialized schools with an advanced level of education (lyceums) - II group (52 people: 22 boys and 30 girls). The age of graduates was 16-17 years.

The first stage. The scientific and methodological literature on a chosen topic was analyzed, a profile was developed that included 24 common questions (anthropometric criteria, main components of school day etc.) and a standardized questionnaire "Stress resistance" [8]. English version of the questionnaire was published online as a Google form.

The second stage. During the vacation period (August, 2019) the evaluation of heart rate variability (HRV) was provided by means of the PRECISE diagnostics (10 students from I group and 16 from the second).

During the studying period (November - December 2019) a questionnaire with the use of the profile mentioned above was conducted in classes by means of respondents filling with its further attachment to an individual envelope.

The comparison group consisted from 22 teenagers (middle age (18.0 \pm 1.2$)$ years), among them there were 9 boys and 13 girls from different countries (Lithuania, Finland, Denmark, the USA, Portugal, Spain, Israel, the UK, Germany, France) that were invited to online questioning through Facebook where the Google form of the questionnaire was put.

After the questioning the evaluation of the heart rate variability by means of the PRECISE diagnostics was conducted among the teenagers of the first and the second groups (18 and 28 student appropriately).

The third stage. Creation of electronic database and statistic analyzing.

Body mass index (BMI) was calculated and evaluation was given, taking into account gender and age standards [22]. Analyze of the main components of the studying day was provided according to the results of the questionnaire. The level of stress resistance was set using the questionnaire "Stress resistance" with the help of anonymous questioning, conducted during the training period. 
For studying the peculiarities of vegetative adaptive reactions the HRV was analyzed and defined using the PRECISE diagnostics. The following indicators were analyzed as sympathovagal balance HF/LF for determination of vegetative tonus, stress index, RMSSD - square root from the mean square of the difference between the values of successive pairs of intervals NN that evaluates level of adaptation; and general spectrum power that reproduces the total effect on the heart rate of all the regulation levels and demonstrates the capacities of the functional organism's reserves [23, 24].

To determine the HRV using the PRECISE diagnostics there was gained an information agreement from child's parents.

Statistical processing of data was conducted by means of computer programs such as Statistica 6.0 and Microsoft Excel 7.0. The evaluation of statistical significance of distinctions between responses distribution in comparison groups was done using the Student's criterion and the criterion " $\chi \mathrm{i}$-square"; to determine a relation between indicators there was used a correlation analysis with calculation of Spearmen's rank correlation coefficient.

\section{Results}

According to the results of anthropometric data, a correspondence between teenagers' weight and height was set, calculating the BMI: $71.8 \%$ and $84.6 \%$ in I and II group appropriately (table 1).

Table 1

BMI distribution of teenagers by gender and type of educational institution

\begin{tabular}{|c|c|c|c|c|c|c|}
\hline \multirow[t]{2}{*}{ BMI indicators } & \multicolumn{3}{|c|}{ I group } & \multicolumn{3}{|c|}{ II group } \\
\hline & $\begin{array}{c}\text { Boys } \\
(n=15)\end{array}$ & $\begin{array}{c}\text { Girls } \\
(n=17)\end{array}$ & $\begin{array}{c}\text { Total } \\
(n=32)\end{array}$ & $\begin{array}{c}\text { Boys } \\
(n=22)\end{array}$ & $\begin{array}{c}\text { Girls } \\
(n=30)\end{array}$ & $\begin{array}{c}\text { Total } \\
(\mathrm{n}=52)\end{array}$ \\
\hline Low & $\begin{array}{c}1 \\
(6,7 \%)\end{array}$ & $\begin{array}{c}2 \\
(11,8 \%)\end{array}$ & $\begin{array}{c}3 \\
(9,4 \%)\end{array}$ & $\begin{array}{c}1 \\
(4,5 \%)\end{array}$ & $\begin{array}{c}2 \\
(6,7 \%)\end{array}$ & $\begin{array}{c}3 \\
(5,8 \%)\end{array}$ \\
\hline Normal & $\begin{array}{c}8 \\
(53,3 \%)\end{array}$ & $\begin{array}{c}15 \\
(88,2 \%)\end{array}$ & $\begin{array}{c}23 \\
(71,8 \%)\end{array}$ & $\begin{array}{c}16 \\
(72,7 \%)\end{array}$ & $\begin{array}{c}28 \\
(93,3 \%)\end{array}$ & $\begin{array}{c}44 \\
(84,6 \%)\end{array}$ \\
\hline High & $\begin{array}{c}6 \\
(40,0 \%)\end{array}$ & 0 & $\begin{array}{c}6 \\
(18,8 \%)\end{array}$ & $\begin{array}{c}2 \\
(9,2 \%)^{*}\end{array}$ & 0 & $\begin{array}{c}2 \\
(3,8 \%)^{* *}\end{array}$ \\
\hline Obesity & 0 & 0 & 0 & $\begin{array}{c}3 \\
(13,6 \%)\end{array}$ & 0 & $\begin{array}{c}3 \\
(5,8 \%)\end{array}$ \\
\hline Average BMI & $22,7 \pm 0,87$ & $20,53 \pm 0,40$ & $21,58 \pm 0,49$ & $23,15 \pm 1,02$ & $20,16 \pm 0,38$ & $21,42 \pm 1,52$ \\
\hline
\end{tabular}

Remarks:

1. $*-\mathrm{p}<0,05-\mathrm{a}$ significant difference in BMI indicators among boys of the I and II groups;

2. $* *-p<0,05-$ a significant difference in indicators of the I and II groups.

High BMI was detected in 40,0 \% of I group that is significantly higher than in lyceum students $(p<0,05)$, among which obesity has been recorded only in single cases; lower BMI was detected in a small number of teenagers with almost the same frequency in groups, not depending on the age.

In the comparison the majority of teenagers had normal BTI too, and only in single cases in boys as well as in girls higher or lower weight was detected.

It was found that the majority of teenagers in Dnipro, regardless of gender, attended additional out-of-school activities (so-called tutors). At the same time, in comparison with comprehensive school students, lyceum students significantly more often studied with tutors $(78,1 \%$ and 94,2\%, accordingly, in I and II groups, $\mathrm{p}<0,05)$. The duration of such classes was also significantly longer in II group: children spent from 2 to 14 hours per week, which averages consisted $(6.3 \pm 0.8)$ hours in I group, while there were $(4.3 \pm 0.6)$ hours in II group $(\mathrm{p}<0.05)$. 
In the comparison group, the frequency of additional classes was much lower, even in II group $(\mathrm{p}<0,05)$, but it should be noted that in foreign countries tutoring is not usually practiced, and additional classes are held only at the request of students in schools (on breaks or just after lessons).

The analysis of the time that teenagers spent on gadgets showed that the majority of I group of teenagers $(65,6 \%)$ and foreign graduates $(68,2 \%)$ spent with gadgets from 3 and more hours, with a predomination among girls. While more than half of lyceum students limited the use of gadgets to 1-3 hours $(61,5 \%)$, regardless of gender $(\mathrm{p}<0,05)$. Teenagers who spent a minimum amount of time with gadgets (up to 1 hour) were only among lyceum students $(\mathrm{p}<0,05)$. A small number of I group graduates $(3,1 \%)$ and $13,6 \%$ of the comparison group spent all their free time with gadgets.

An important component in lives of teenagers is physical activity (PA). In studying the position of PA in the lives of graduates, we, first of all, found out which medical admission group students had for physical education classes. Thus, among lyceum students the number of children in the main admission group was significantly lower $(59,6 \%)$, in contrast to group $(87,5 \%)$ and the comparison group $(90,9 \%, \mathrm{p}<0,05)$, while as an especial group had only lyceum teenage students $(19,2 \%)$, in contrast to I group and the comparison group $(\mathrm{p}<0,05)$.

After school, the majority of teenagers in Dnipro and foreign students took an additional PA in various sports centers, with a significant predominance of such children in I group $(87,5 \%)$ and the comparison group $(90,9 \%)$, regarding to lyceum students $(57,7 \%, \mathrm{p}<0.05)$, while no significant gender differences in participation in sports sections were detected.

On average, the frequency of these exercises and their duration was also significantly higher in students of I group and the comparison group, in contrast to teenagers of II group $(p<0,05)$.

We were interested in determining whether the PA of graduates changed in comparison to last year. Thus, it was found that comprehensive school students and teenagers in foreign countries in the majority (90,6\% and 90,2\%) kept their PA level (some even increased), while lyceum students were forced to sharply reduce their PA, mainly for reasons of the high studying load. Only $21,2 \%$ of them kept their last year's level of the PA, and more than one third of them $(36,5 \%)$ completely stopped PA exercises, which was significantly different from I group and the comparison group $(\mathrm{p}<0,05)$.

This, in its turn, affected the self-esteem of calisthenics: only one third of lyceum graduates (30,8\%) considered themselves physically developed (mostly young men), in contrast to comprehensive school graduates and foreign students, among whom the majority were satisfied with their physical shape $(75,0 \%$ and $63,6 \%$ accordingly, $\mathrm{p}<0,05)$.

While analyzing the responses of teenagers to the sleep duration, it was found that the average sleep duration of lyceum students was $(6,43 \pm 0,21)$ hours (with a slight decrease among girls) and more than an hour less than in I group and the comparison group $(\mathrm{p}<0,05)$.

While analyzing the answers to the question "How often do you awake at night?" it was found that lyceum graduates most often awaked at night $(40,4 \%$ of cases, regardless of gender, $\mathrm{p}<0,05)$, while sound sleep, without breaks, was noted by the majority of teenagers of I group $(68,8 \%)$ and the comparison group $(72,7 \%, \mathrm{p}<0,05)$, in contrast to II group, where the number of such students was only $28,9 \%$ ( $\mathrm{p}<0,05)$. To the question "Do you sleep enough sleep?" different answers were got: more often, a feeling of sufficient sleep was found among foreign graduates $(50,0 \%)$, the least - among lyceum students $(3,9 \%, \mathrm{p}<0,05)$, and every second of them does not sleep enough $(\mathrm{p}<0,05)$.

Taking into account the literature data about the importance of sufficient sleep duration for teenagers' health $[12,25,26,27]$, we found that the significant decrease in the duration and quality of sleep among lyceum students may be the basis for decreasing of stress resistance and acquiring of many diseases, including cardiovascular ones.

To determine the possible consequences of intense studying load, sleep disorders and reduced PA in graduates, we analyzed their stress resistance. 
The analysis of the responses from the questionnaire "Resistance to stress" showed that among teenagers of I group the level of resistance to stress (LR) during the maximum studying load was almost equally distributed between "high" and "moderate" (53,1\% and 40,6\% accordingly), with the maximum incidence of high LR among boys $(66,7 \%)$, while sharply reduced LR was found only in girls, in a small number $(11,7 \%)$.

Among lyceum students, the frequency of sharply reduced LR was significantly higher than in I group $(p<0,05)$, and occurred in every second teenager $(50,0 \%)$, and in girls twice as often as in boys $(63,3 \%$ and $31,8 \%$, respectively, $\mathrm{p}<0,05)$. High LR was found in only $11,5 \%$ of lyceum students, which is significantly less than in I group and comparison group $(p<0,05)$. The frequency of moderately low LR was observed in an average of one third of teenagers without significant difference in groups. In the comparison group, the frequency of high LR was significantly higher compared to students of both groups, and amounted to $81,8 \%(\mathrm{p}<0,05)$.

It should be noted that while answering the question "Are there other factors that cause feelings of anxiety and depression?", Ukrainian graduates noted the following ones: fear of passing an external independent evaluation, the need to enter higher education, because parents insist, and boys - to prevent service in the army, etc. Foreign graduates, not only having 12 years of comprehensive education, i.e. graduating at the age of 18-19, but also often (especially in European countries) take a gap year to be able to master themselves, to make a more informed choice of profession.

The correlation analysis showed a connection between increasing of the time for tutors and improving of the school performance $(\mathrm{r}=0,562)$, worsening of the sleep quality (more frequent night awaking, $r=0,547)$, decreasing of the PA time $(r=-0,590)$, decreasing of the self-esteem of the calisthenics $(r=-0,392)$, decreasing of the level of stress resistance $(r=-0,307)$.

The increase of time with gadgets was connected with decreasing of the school performance $(\mathrm{r}=-0,386)$, increasing of the night awaking $(\mathrm{r}=-0,296)$, worsening of the quality of falling asleep ( $\mathrm{r}$ $=-0,417)$.

A significant number of connections was found in the analysis of the graduate's PA, increasing the duration of that per week led to increasing of the sleep duration $(r=0,300)$, decreasing of the night awaking $(r=0,685)$, increasing of sense of enough sleep $(r=0,414)$, increasing of the self-esteem of the calisthenics ( $r=0,711)$, increasing of the level of stress resistance $(r=0,485)$.

The correlation analysis of sleep indicators found the following: increasing of sleep duration correlated with decreasing of time for classes with tutors $(\mathrm{r}=-0,321)$, decreasing of time spent with gadgets $(\mathrm{r}=-0,569)$, increasing of the PA time per week $(\mathrm{r}=0,300)$, increasing of the self-esteem of their calisthenics $(r=0,438)$, increasing of the stress resistance $(r=0,526)$. The sleep quality (night awaking, feeling of enough sleep) was also strongly connected with all of these parameters $(\mathrm{p}<0,05)$.

The level of stress resistance correlated with a number of parameters of a studying day of graduates and increased with rising age of the students $(r=0,321)$, their weight and BMI $(0,513)$, increasing of the sleep hours $(\mathrm{r}=0,526)$, decreasing of the frequency of night awaking $(\mathrm{r}=-0,599)$, the time for tutoring $(r=-0,658)$, the time for the PA $(r=-0,507)$, increasing of the self-esteem of their calisthenics $(\mathrm{r}=0,499)$.

Therefore, the changes we found in the quality of life in a significant number of teenage graduates (decreasing of the duration and quality of sleep, of the stress resistance, of the selfesteem, etc.) is connected mainly with studying load and decreasing of the PA, may be the basis for shifts of the cardiovascular system adaptive capabilities.

When esteeming heart rate variability (table 2), it was found that the SDDN index, the decrease in which indicates the risk of cardiovascular disease, on average, was probably lower in lyceum teenagers in comparison with comprehensive school children, where this figure was observed, on average, within normal limits $(7,29 \pm 5,10) \mathrm{m} / \mathrm{s}(\mathrm{p}<0,05)$. In general, the majority of teenagers in I group $(93,3 \%)$ had no risk of getting a cardiovascular pathology, while more than half of lyceum students $(60,7 \%)$ had an increased value $(\mathrm{p}<0,05)$. 
Heart rate variability index of teenagers during the training period according to PRECISE diagnosis

\begin{tabular}{|c|c|c|c|c|c|c|}
\hline \multirow[t]{2}{*}{ Index } & \multicolumn{3}{|c|}{ I group } & \multicolumn{3}{|c|}{ II group } \\
\hline & $\begin{array}{l}\text { Boys } \\
(n=6)\end{array}$ & $\begin{array}{c}\text { Girls } \\
(\mathrm{n}=12)\end{array}$ & $\begin{array}{c}\text { Total } \\
(\mathrm{n}=18)\end{array}$ & $\begin{array}{l}\text { Boys } \\
(n=10)\end{array}$ & $\begin{array}{c}\text { Girls } \\
(\mathrm{n}=18)\end{array}$ & $\begin{array}{c}\text { Total } \\
(\mathrm{n}=28)\end{array}$ \\
\hline \multicolumn{7}{|c|}{ SDNN: } \\
\hline Absence of cardiovascular risk & $6(100,0 \%)$ & $9(75,0 \%)$ & $\begin{array}{c}15 \\
(93,3 \%) \\
\end{array}$ & $6(60,0 \%)$ & $5(27,8 \%)$ & $\begin{array}{c}11 \\
(39,3 \%)^{*}\end{array}$ \\
\hline Increased cardiovascular risk & 0 & $3(25,0 \%)$ & $3(16,7 \%)$ & $4(40,0 \%)$ & $13(72,2 \%)$ & $\begin{array}{c}17 \\
(60,7 \%)^{*}\end{array}$ \\
\hline \multicolumn{7}{|c|}{ RMSSD: } \\
\hline Good physical conditioning & $2(33,3 \%)$ & 0 & $2(11,1 \%)$ & $1(10,0 \%)$ & 0 & $1(3,6 \%)$ \\
\hline Normal adaptation & $4(66,6 \%)$ & $\begin{array}{c}11 \\
(91,7 \%)\end{array}$ & $\begin{array}{c}15 \\
(83,3 \%) \\
\end{array}$ & $6(60,0 \%)$ & $10(55,6 \%)$ & $\begin{array}{c}16 \\
(57,1 \%)^{*}\end{array}$ \\
\hline $\begin{array}{l}\text { Adaptation } \\
\text { disruption / impairment }\end{array}$ & 0 & 0 & 0 & $3(30,0 \%)$ & $8(44,4 \%)$ & $\begin{array}{c}11 \\
(39,3 \%)^{*}\end{array}$ \\
\hline \multicolumn{7}{|c|}{ LF/HF: } \\
\hline Vagotonia & $3(50,0 \%)$ & $7(58,3 \%)$ & $\begin{array}{c}10 \\
(55,6 \%) \\
\end{array}$ & $5(50,0 \%)$ & $5(27,8 \%)$ & $10(35,7 \%)$ \\
\hline Eutonia & $3(50,0 \%)$ & $2(16,6 \%)$ & $5(27,8 \%)$ & $3(30,0 \%)$ & 0 & $3(10,7 \%)$ \\
\hline Sympathicotonia & 0 & $3(25,0 \%)$ & $3(16,7 \%)$ & $2(20,0 \%)$ & $13(72,2 \%)$ & $\begin{array}{c}15 \\
(53,6 \%)^{*}\end{array}$ \\
\hline \multicolumn{7}{|c|}{ Total power (TP): } \\
\hline Exhaustion & 0 & $1(8,3 \%)$ & $1(5,5 \%)$ & $1(10,0 \%)$ & $5(27,8 \%)$ & $6(21,4 \%)^{*}$ \\
\hline Mental activity prevails & $1(16,6 \%)$ & $6(50,0 \%)$ & $7(38,8 \%)$ & $6(60,0 \%)$ & $5(27,8 \%)$ & $14(50,0 \%)$ \\
\hline Physical activity prevails & $5(83,3 \%)$ & $5(41,6 \%)$ & $\begin{array}{c}10 \\
(55,5 \%)\end{array}$ & $3(30,0 \%)$ & $8(44,4 \%)$ & $8(28,6 \%)^{*}$ \\
\hline Hormonal balance check & 0 & 0 & 0 & 0 & 0 & 0 \\
\hline \multicolumn{7}{|c|}{ SI (stress index): } \\
\hline Normal & $5(83,3 \%)$ & $9(75,0 \%)$ & $14(77,8)$ & $7(70,0 \%)$ & $6(33,3 \%)$ & $\begin{array}{c}13 \\
(46,4 \%)^{*}\end{array}$ \\
\hline Anxiety & $1(16,6 \%)$ & $3(25,0 \%)$ & $4(22,2 \%)$ & $3(30,0 \%)$ & $12(66,7 \%)$ & $\begin{array}{c}15 \\
(53,6 \%)^{*}\end{array}$ \\
\hline
\end{tabular}

Remark. $*-p<0,05-$ a significant difference in indexes of the I and II groups.

In the studied teenagers, the average indicators of RMSSD, which characterized the organism adaptive capacity, were within normal limits, but with a probable decrease in this indicator in lyceum students up to $(42,03 \pm 4,73) \mathrm{m} / \mathrm{s}$ compared with comprehensive school students $(73,04 \pm 5,18) \mathrm{m} / \mathrm{s}(\mathrm{p}<0,05)$. The analysis of specific data founded that in I group children with normal adaptation prevailed $(83,3 \%)$. Unfortunately, more than one third of lyceum students $(39,3 \%)$ during the period of maximum studying load (end of the first semester) showed signs of maladaptation (failure) of adaptation $(\mathrm{p}<0,05)$, which indicates a weakening of parasympathetic effects on heart rate with further violation of the adaptation of these children.

The analysis of the LF/HF ratio founded a significant increase in children of II group $(1,32 \pm 0,15)$, which indicates increasing of sympathetic regulation and decreasing of parasympathetic effects on cardiac activity $(\mathrm{p}<0,05)$. The vegetative balance of comprehensive school graduates was maintained on average.

The analysis of ANS different types frequency among teenagers who were examined showed that in I group the prevalence of vagotonia $(55,6 \%)$ and eutonia $(27,8 \%)$, with the latter predominating in teenagers, while more than half of lyceum graduates $(53,6 \%)$ showed sympathicotonia (with a predomination among girls), which is significantly higher than in I group $(\mathrm{p}<0,05)$.

Therefore, the studies above showed the presence of sympathetic division activation of lyceum students' ANS, in contrast to comprehensive school students, who had eutonia on average. 
According to the data in the table, the total spectrum power was preserved on average in both groups of graduating teenagers, but when analyzing the percentage of different variants of TP, it was studied out that spectrum frequency characteristic of physical activity $(55,5 \%, \mathrm{p}<0,05)$ was dominant among students of I group; TP, characteristic of mental activity (50,0\%) was present among lyceum students, but signs of adaptive potential exhaustion were significantly more common among teenagers of II group.

Analysis of the SI index (stress index) showed a probable increase in its average figures for adolescent lyceum students - up to $(115,73 \pm 12,26)$ in contrast to comprehensive school students, whose values of the stress index were on average normal . In general, most teenagers of I group $(77,8 \%)$ had normal values of this indicator $(\mathrm{p}<0,05)$, and only $22,2 \%$ showed signs of anxiety, while more than half of lyceum students $(53,6 \%)$ were identified with signs of anxiety $(\mathrm{p}<0,05)$.

While analyzing the level of stress resistance depending on the tonus of ANS, the highest frequency of high LR was found in teenagers of I group: 100,.0\% - eutonia, and 80,0\% - vagotonia $(\mathrm{p}<0,05)$, at the same time, reduced and sharply reduced LR was detected only in sympathicotonia (66,7\% and 33,3\%, respectively). The distribution of different levels of stress resistance did not differ significantly among lyceum students in the vagotonia state during the period of maximum training load, the frequency of high LR also prevailed in the eutonia state, and the frequency of sharply reduced LR prevailed $(80,0 \%)$ in the sympathicotonia state.

It should be indicated that none of 6 teenagers who did not reduce their PA in the final class noted a disruption of adaptation, despite the fact that sympathicotonia was present in half of them, and the total spectrum power (TP) was found only in those graduates $(28,6 \%$ of cases) who did not reduce their PA which confirms its importance in maintaining the adaptation of the organism [1].

Due to the fact that some teenagers $(10$ - comprehensive school students and 16 - lyceum students) had their HRV analyzed using PRECISE diagnostics during the vacation period (August 2019), we were able to compare this data to the one obtained during the school period. Thus, regardless of the educational process period, the SDDN index of the students of I group in the vast majority $(90,0 \%)$ did not indicate the risk of CVS pathology, while comprehensive school graduates showed a tendency to increased risk of CVS pathology - from $25,0 \%$ during the vacation period to $56,5 \%$ - during the study period $(\mathrm{p}<0,05)$.

Analysis of the adaptive capacity of the surveyed teenagers, according to RMSSD, showed that no violation of adaptation was detected in I group, both during the vacation and in the study period, while training load among comprehensive school students during the school period led to a decrease in normal RMSSD - from $81,2 \%$ during the vacation period to 50,0\% during the school period $(p<0,05)$ and the appearance of adaptation disorders in $43,7 \%$ of cases $(p<0,05)$.

In the examined teenagers ANS functioned in the imbalance mode of its sympathetic and parasympathetic units with the preponderance of sympathicotonia in comprehensive school students (50,0\% - during the vacation period, 56,3\% - during the school period), while among students of I group, regardless of the period of the study year, preponderance of vagotonia and eutonia $(50,0 \%$ and $30,0 \%$, respectively) occurred.

There was a significant decrease in Total power in $25,0 \%$ of lyceum students during the study period, indicating the exhaustion of body's functional reserves $(p<0,05)$, in contrast to comprehensive school students, among whom reduced body resources occurred less often in the same period.

The frequency of normal stress index was maximum in comprehensive school students during the vacation period $(90,0 \%)$, and during the study period the frequency of this symptom did not differ significantly from the lyceum students during the vacation period $(70,0 \%$ and $81,3 \%$ respectively). More than half of comprehensive school teenagers $(56,3 \%)$ during the study period showed a significant increase in the stress index to the level of "anxiety" $(p<0,05)$.

In the process of communicating with parents to explain the results of the study of heart rate variability, we accidentally found out that a significant fraction of comprehensive school teenagers take nootropics or bio-supplements of psychotropic action.

We were unable to determine the exact data due to a possible breach of ethics. 
Therefore, the analysis of heart rate variability revealed significant disruptions of the adaptive capacity of the cardiovascular system in graduating teenagers with a significant workload.

In order to clarify the possible trigger factors of these changes, we conducted a correlation analysis of the data, which determined that SDDN was accompanied by a numerous interconnections: the risk of CVS pathology increases in girls $(r=0,312)$, increasing time of lessons with a tutor $(r=0,397)$, decrease in time of PA $(r=-0,585)$, decreasing level of stress resistance $(r=-$ $0,452)$, decrease in adaptation potential (RMSSD) $(r=-0,784)$ and TP $(r=-0,902)$, increase in sympathovagal balance in the direction of activating the sympathetic link of ANS $(r=0,572)$ and the stress index $(\mathrm{r}=0,938)$.

The rate of adaptive capacity of the body RMSSD in term increases in teenagers $(r=0,346)$, accompanied by increasing weight and BMI $(r=0,428)$, increasing sleep duration $(r=0,300)$, improvement of sleep quality ( $\mathrm{r}=0.403)$, with decrease in time of lessons with a tutor $(\mathrm{r}=-0.427)$, increase in PA $(r=0,621)$ and the level of stress resistance $(r=0,546)$, and also correlates with all indicators of heart rate variability (increases with decreasing risk of CVS pathology, sympathovagal index towards the parasympathetic nervous system, stress index and with increasing TP).

The sympathovagal balance of $\mathrm{LF} / \mathrm{HF}$ decreased towards the parasympathetic link of ANS with increasing time of PA ( $\mathrm{r}=-0,335)$, which confirms the literature data [28]. The increase in this index was accompanied by increase in the risk of CVS pathology $(r=0,572)$ and stress index $(\mathrm{r}=0,625)$, and decrease in the adaptive potential $(\mathrm{r}=-0,577)$ and TP $(\mathrm{r}=-0,570)$.

The power of the Total power (TP) spectrum increased in teenagers $(r=0,317)$, accompanied by increasing weight and BMI $(r=0,334)$, increasing time of PA $(r=0,408)$ and stress resistance $(\mathrm{r}=0,357)$, decreased with increasing time of lessons with a tutor $(\mathrm{r}=-0,332)$. This indicator also correlated with other HRV indicators as presented above.

Decrease in the level of SI (stress index) was noted which was accompanied by increasing age of teenagers $(\mathrm{r}=-0,262)$, their weight and BMI $(\mathrm{r}=-0,350)$, and growth in lyceum students $(\mathrm{r}=0,454)$, girls $(\mathrm{r}=0,353)$, by sleep deprivation $(\mathrm{r}=0,312)$, increasing time of lessons with a tutor $(\mathrm{r}=0,364)$, decrease in time of PA $(\mathrm{r}=-0,534)$ and the level of stress resistance $(\mathrm{r}=0,500)$. Also, this indicator was closely correlated with all components of HRV: increased with increasing risk of CVS pathology $(r=0,938)$, sympathovagal index towards sympathicotonia $(r=0,625)$, decreased with decreasing adaptive capacity $(\mathrm{r}=0,780)$ and $\mathrm{TP}(\mathrm{r}=0,893)$.

\section{Conclusion}

Graduation classes make significant adjustments to the daily routine of teenagers, especially lyceum students: children's physical activity decreases, sleep duration is reduced and its quality deteriorates. ANS in the examined students operates in the imbalance mode of its sympathetic and parasympathetic links with the preponderance of sympathicotonia accompanied by increased information load. With the increase of the study load, the high level of physical activity and sufficient sleep duration contribute to the preservation of the adaptive capabilities of the cardiovascular system. Assessment of heart rate variability, in particular by means of PRECISE diagnostics, is a highly informative, convenient method that allows estimating the adaptive capacity state of teenager's cardiovascular system, including the severity of stress, and can be recommended for both diagnostic purposes and surveillance of students' health.

\section{References}


1. Kuznetsova O.B. Heart rate variability in the process of educational activity of students with different levels of physical activity: topic of dissertation...candidate of biological sciences: 03.00.13. Chelyabinsk. 2007.

2. Lyashenko V.P., Petrov G.S., Kofan I.M., Mizin V.V. Features of adaptive reactions of students with different areas of study and level of physical activity. Dnipro: Lira; 2018.

3. Malyushina Y.A. Features of resistance to stress at teenage age. Vestnik of Kurgan State University. 2018; 1(48): 35-37.

4. Kessler R.C., Angermeyer M., Anthony J.C., et al. Lifetime prevalence and age-ofonset distributions of mental disorders in the World Health Organization's World Mental Health Survey Initiative. World Psychiatry. 2007; 6: 168-76.

5. Michaela C., Pascoe, Sarah E., Hetrick \& Alexandra G. Parker (2020) The impact of stress on students in secondary school and higher education, International Journal of Adolescence and Youth, 25:1, 104 - 112, DOI: 10.1080/02673843.2019.1596823

6. Grabovska S., \& Musakovska O. (2020). Information overload: the psychological area. Psychological journal, 6(7): 18-29. https://doi.org/10.31108/1.2020.6.7.2

7. Marques A., Silverman M., Sternberg E. Evaluation of stress systems by applying noninvasive methodologies: measurements of neuroimmune biomarkers in the sweat, heart rate variability and salivary cortisol. Neuroimmunomodulation. 2010; 17: 205-8.

8. $\quad$ Kupriyanova R.V., Kuzman Yu. Psychodiagnostics of stress. Kazan; 2012.

9. Michels N., Sioen I., Clays E. Children's heart rate variability as stress indicator: association with reported stress and cortisol. Biol Psychol. 2013; 94: 433-40.

10. Oberle Kimberly E., Schonert-Reichl A. Stress contagion in the classroom? The link between classroom teacher burnout and morning cortisol in elementary school students. Social Science \& Medicine. 2016; 159: 30-37.

11. Kim H.G., Cheon E.J., Bai D.S. Stress and Heart Rate Variability: A Meta-Analysis and Review of the Literature. Psychiatry Investig. 2018; 15(3): 235-245.

12. Rodríguez-Colón S.M., He F., Bixler E.O., et al. Sleep variability and cardiac autonomic modulation in adolescents - Penn State Child Cohort (PSCC) study. Sleep Med. 2015; 16(1): 67-72.

13. Vershinina S.V., Kotova O.V., Ryabokon I.V. Stress in children and adolescents: causes and consequences, treatment and prevention. URL: https://medi.ru/info/3059/ (date of access: 05/29/2021).

14. Zaitseva O.I., Kolodyazhnaya T.A. State and relationship of the vegetative nervous system with the psychoemotional status of schools. Modern problems of science and education. 2016. URL: http://www.science-education.ru/ru/article/view?id=24193 (date of access: 05/29/2021).

15. Lyashenko V.P., Dregval I.V. The vegetative nervous system. Dnipro: 2005.

16. Salko T.I., Lukina Yu.S., Dubinin V.V. Vegetative reactivity and the system of physical activity. URL: https://sibac.info//archive/humanities/5.pdf (date of access: 05/29/2021).

17. Rotenberg S., McGrath J. Inter-relation between autonomic and HPA axis activity in children and adolescents. Biol. Psychol. 2016; 117: 16-25.

18. Clinical investigation report. Randomized, prospective, sham-controlled, blinded, cross-over clinical study of the effect of the virtual reality (VR) technology on the recovery of the indicators of the autonomic nervous system in healthy volunteers affected by moderate stress. Pure Purr virtual reality techn., 1000 N. West St., Ste 1501, City of Wilmington, Delaware 19801, 2019. URL: https: //www.clinicaltrials.gov/ProvidedDocs/52/NCT03532152/Prot_000.pdf (date of access: 05/29/2021).

19. PRECISE automated ECG interpretation. Calofornia 90291 United States. 2018. URL: www.precisecloud.online (date of access: 05/29/2021).

20. PRECISE Cloud ECG Interpretation: Breakthrough Invention That One Day Might Save Your Life, 2017. URL: https://www.prweb.com/releases/2017/12/prweb15027249.htm (date of access: 05/29/2021). 
21. Vasylenko Y., Aganov S. Clinical Study of the Effect of the Virtual Reality (VR) Technology on Recovery of the Indicators of the Autonomic Nervous System in Healthy Volunteers Affected by Moderate Stress. ClinicalTrials. gov Identifier: NCT03532152. 2018.

22. The Practical Guide Identification, Evaluation, and Treatment of Overweight and Obesity in Adults, 2000. URL: https://www.nhlbi.nih.gov/files/docs/guidelines/prctgd_c.pdf. (date of access: 05/29/2021).

23. Camm J., Malik J., Bigger T. Heart rate variability. Standards of measurement, physiological interpretation, and clinical use Task Force of The European Society of Cardiology and The North American Society of Pacing and Electrophysiology. European Heart Journal. 1996; 17: 354-38.

24. Prineas R., Crow R., Blackburn H. The Minnesota Code Manual of Electrocardiographic Findings including measurement and comparison with the Novacode. Standards and Procedures for ECG Measurement in Epidemiologic and Clinical Trials. Second Edition New and Enlarged. Springer-Verlag London Limited, 2010.

25. Michels N., Clays M., De Buyzere, Vanaelst B. Children's sleep and autonomic function: low sleep quality has an impact on heart rate variability. SLEEP. 2013; 36(12): 19391946.

26. Wheaton A.G., Jones S.E., Cooper A.C. Short Sleep Duration Among Middle School and High School Students. MMWR Morb. Mortal Weekly Rep. 2018; 67(3): 85-90.

27. Zambotti M., Goldstone A., Colrain I. Insomnia disorder in adolescence: Diagnosis, impact, and treatmen. Sleep Med Rev. 2018; 39: 12-24.

28. Sacha J., Werner P., Jeleń. Heart Rate Variability and other Autonomic Markers in Children and Adolescents. Lausanne: Frontiers Media SA, 2019: 185. 